\title{
Anxiety, and the suppressing effect of immediate punishment on a rewarded response'
}

\author{
A. H. SHAPIRO \\ UNIVERSITY OF WATERLOO
}

Suppression of an immediately rewarded (money) response which was also immediately punished (electric shock) was examined in relation to anxiety in 58 normal Ss. High-anxious $S s$ displayed the least response suppression ( $p<.05)$. In addition, these correlations appeared most strongly when reward and punishment were administered on similar schedules.

Great individual differences are observed in people under stress or conflict conditions (Deese, Lazarus, \& Keenan, 1953) and one crucial factor may be drive level defined as anxiety (Malmo, 1962).

Hull's (1943) concept of drive indicates that a correct "simple" instrumental response, firmly established during training would persist for a longer duration during extinction in high-drive Ss than in low-drive Ss. Thus, Hull's theory would imply that high drive may also hinder suppression of a response receiving punishment.

In view of this prediction, the present experiment investigated drive level (anxiety) related to the suppression of an immediately rewarded (money) response which was also immediately punished (electric shock). Since an intermittent or continuous reinforcement schedule is known to influence response strength (Vogel-Sprott, 1966), this study also manipulated the schedules of reward and punishment.

Method

Fifty-eight volunteers enrolled in undergraduate psychology courses at the University of Waterloo served as Ss. They were randomly assigned to four different groups, three of which contained 15 Ss. The fourth contained 13 Ss.

One-half of all Ss were trained on a continuous (100\%) reward schedule (CR), and the other half were trained with random (50\%) partial reward (PR). These two groups then were subdivided so that one CR and one PR subgroup received continuous punishment (CP), and one PR subgroup received partial punishment (PP).

The equipment consisted of a three-button response panel, a penny reward dispenser, a signal generator, and a shock generator with leads to finger electrodes. This apparatus was interconnected so that one sequence of three button presses (e.g, 3-1-2) activated the reward dispenser for immediate delivery of a penny to the S. A jewelled light, $3 / 4$ in. in diameter was located on the response panel above each button. Each light lit whenever its corresponding button was pressed, and remained on until the next trial began. An intertrial interval of $15 \mathrm{sec}$. was employed. Punishment was administered by an $850 \mathrm{v}$ shock generator which de- livered a .10 sec. shock of 1.75 ma. Shock and reward schedules were independently programmed by the apparatus.

Drive level was measured by the Taylor Manifest Anxiety scale (MAS) (Taylor, 1953) which S completed before he was seated at a desk in front of the apparatus. He was informed that he would have a number of trials on a button-pressing task for pennies which he could keep. Trials were signaled by the offset of the panel lights. On each trial, $S$ was free to press the three buttons singly in any order he wished provided that no button was pressed twice. This meant that only six different combinations of the three buttons were possible. The penny was administered for only one of these combinations but Ss were not given this information. The $E$ attached finger electrodes to S's non-dominant hand and mentioned that at some time he may feel a slight electric shock that would not be harmful. The $\mathrm{S}$ was also told that there was a way of working which would allow him to avoid the shock and he should do this if he could. When $S$ performed the one rewarded sequence on five consecutive trials, acquisition trials terminated and the punishment test immediately began.

Twenty immediate punishment trials were administered according to the differing punishment schedules, while the training schedules were maintained throughout. Punishment was administered on the third button press of the one rewarded response whenever it was displayed. The number of punished responses occurring during the 20 punishment trials were recorded for each $S$. Results

The mean MAS score was $17.6(\operatorname{mdn}=17.0, \mathrm{SD}=7.34)$ and the mean number of punished responses was 11.1 $(\mathrm{mdn}=11.0, \mathrm{SD}=5.57)$.

Spearman's rho (Seigel, 1956) was employed to assess the correlation between MAS scores and punished responses. A significant positive correlation was obtained $\left(r_{\mathrm{S}}=+0.310, \mathrm{n}=58, \mathrm{p}<.05>.01\right.$ one tailed test). The Ss who displayed more punished responses obtained higher MAS scores.

Similar analyses were also conducted individually for the four groups. Mean MAS scores for each group were: PR-PP, $16.6(\mathrm{SD}=6.02)$; $\mathrm{PR}-\mathrm{CP}, 17.8(\mathrm{SD}=8.20)$; CR-CP, $18.0 \quad(\mathrm{SD}=6.93)$; CR-PP, $14.47 \quad(\mathrm{SD}=4.55)$. Spearman Rank Correlation Coefficients yielded significant positive correlations between MAS scores and punished responses in only two of the groups. The PR-PP group $\left(r_{s}=+0.444, n=15, p<.05>.01\right)$, and the CR-CP group $\left(r_{S}=+0.548, n=13, p<.05>.01\right)$. Nonsignificant 
positive correlations were obtained for the PR-CP group $\left(r_{S}=+0.009, n=15\right)$, and CR-PP group $\left(r_{S}=+0.068\right.$, $\mathrm{n}=15$ ) (one tailed tests).

\section{Discussion}

High-drive Ss exhibited less response suppression overall than did low-drive Ss who suppressed the punished responses rapidly. This finding is consistent within the framework proposed by Hull (1943) relating drive level to resistance to extinction of a simple habit. Assuming button pressing to be a simple habit, the observed effect of punishment on the response of high-drive Ss appears similar to that which would be expected during extinction.

Further analysis of the data revealed significant positive correlations between anxiety and punished responses in the $P R-P P$ group and $C R-C P$ group only. Since drive level means are relatively constant across all groups, the results indicate that consistency between schedules of reward and punishment may be an extremely important variable in learning of response suppression. If one assumes that inconsistent reinforcement condition may actually facilitate discrimination between acquisition and punishment phases of the experiment, then the results of this study suggest that high-drive Ss may be less able to discriminate adequately between the training and punishment conditions when reward and punishment schedules are identical. As a consequence high-drive Ss would be expected to emit more punished responses only in the PR-PP and
CR-CP groups. It may be suggested that perhaps situational arousal, due to a possible "threatening" nature of these tasks prohibited rapid modification of response in the high-drive Ss (Malmo, 1958; Spence, 1958) while the low-drive Ss performed with maximum efficiency. Physiological measures of arousal of Ss during the experiment would be required to examine this suggestion for future research.

\section{References}

Deese, J., Lazarus, R. S., \& Keenan, J. Anxiety, anxiety reduction, and stress in learning. J. exp. Psychol, 1953, 46, 55-61. Hull, C. L. Principals of behavior. New York: Appleton, 1943. Malmo, R. B. In M. R. Jones (Ed.), Nebraska symposium on motivation. University of Nebraska Press, Lincoln, Nebraska, 1958. Pp. 229-265.

Malmo, R. B. Activation. In A. J. Bachrach (Ed.), Experimental foundations of clinical psychology. New York: Basic, 1962. Pp. 386-422.

Siegel, S. Nonparametric statistics. New York: McGraw-Hill, 1956. Spence, K. W. A theory of emotionally based drive (D) and its relation to performance in simple learning situations. Amer. Psychol., 1958, 13, 131-141.

Taylor, Janet A. A personality scale of manifest anxiety. $J$. exp. Psychol., 1953, 48, 285-290.

Vogel-Sprott, Muriel D. Suppression of a rewarded response by punishment as a function of reinforcement schedules. Psychon. Sci., 1966, 5, 395-396.

\section{Note}

1. This research was supported by a NRC grant APA-93 to M. D. Vogel-Sprott whose assistance is gratefully acknowledged. 